\title{
LA EVOLUCIÓN EN EL CONCEPTO DE PROPIEDAD EN LA DOCTRINA SOCIAL DE LA IGLESIA
}

Hugo García Salvattecci*

\begin{abstract}
RESUMEN
El magisterio social pontificio manifestó su explícito reconocimiento de la propiedad privada como un legítimo derecho que le corresponde a todo hombre: poseer, disponer y disfrutar de los bienes que obtenga mediante el fruto de su trabajo. Este derecho es fundamental e inalienable porque se funda en la propia naturaleza humana. La iglesia a través de su magisterio pontificio, sobre todo a partir del papa León XIII al tratar el tema de la propiedad privada no asumió un concepto nuevo; sino que apoyándose en las sagradas escrituras y en la tradición expuso su pensamiento en torno al ejercicio de este derecho desligándolo de ser carácter sagrado y exclusivo. Manifestó que si bien este derecho debe ser reconocido por el Estado, su ejercicio no debe significar detrimento en el derecho de las otras personas ni atentar contra el bien común, al cual está llamado la sociedad en pleno.
\end{abstract}

PALABRAS CLAVE: Propiedad privada. Derecho natural. Bien común. Justicia social. Justiprecio. Salario justo. Expropiación. Estatismo.

\section{EVOLUTION OF THE PROPERTY CONCEPT IN THE SOCIAL DOCTRINE OF THE CHURCH}

\begin{abstract}
The Pontifical Social Doctrine expressed its explicit recognition of the private property as a legitimate right corresponding to every man: to possess, provide and enjoy the goods resulting from work. This right is fundamental and inalienable, since it is based in the human nature. The Church, through its Pontifical Doctrine, particularly from Pope León XIII when mentioning the subject related to the private property did not assume a new concept, but basing on the Holy Scriptures as well as in the tradition, mentioned what it thought regarding the exercise of this right, separating it from the exclusive and holy character. It has also said that if this right must be recognized by the State; its exercise should not represent detriment in other people's right, nor threaten against commonwealth, which is called the full society.
\end{abstract}

KEYWORDS: Private property, Natural right. Commonwealth. Social Justice. Valuation. Fair Salary, Expropriation, State Control.

\footnotetext{
*Doctor en letras por la Pontificia Universidad Católica del Perú. Bachiller en Ciencias Administrativas y Contador Público por la PUCP. Docente Universitario. Conferencista. Fue Superintendente de Banca y Seguros. Ha investigado y publicado sobre el pensamiento político peruano y también sobre teología social.
} 
Cuando el Cristianismo se propagó por el mundo helénico las cosas cambiaron radicalmente, pues para el mundo greco-romano la propiedad tenía un carácter casi sagrado. Aunque todavía San Agustín soñaba con una sociedad solidaria donde los bienes estuviesen al exclusivo servicio del quien realmente los necesitase. Varios siglos después, Santo Tomás de Aquino vería en la propiedad más que un derecho natural una exigencia social. Incluso, para el Doctor Angélico, si un hombre padeciese hambre y para saciarlo no tuviese más remedio que tomar lo que a otro le sobra, no efectuaría un robo, pues se estaría apropiando de lo que naturalmente le pertenece, ya que los derechos naturales tienen prioridad sobre las exigencias sociales.

En lo que se refiere propiamente a la denominada doctrina social de la Iglesia, vemos que hay una clara evolución no propiamente en el contenido del tema, pero sí en precisar los alcances y los límites de la propiedad privada. León XIII, que es el Papa con el que se inicia la doctrina social de la Iglesia denominada contemporánea, por los condicionantes históricos de ese entonces, defiende de modo decidido y radical el derecho a la propiedad privada. Posteriormente, y de modo paulatino, si bien continuará defendiendo siempre el derecho a la propiedad privada, la Iglesia insistirá también en la función social que debe cumplir para que se justifique moralmente y admitirá el derecho del Estado a limitarla pero sólo en función del bien común.

\section{León XIII}

León XIII, en la "Rerum Novarum", señala que el "poseer algo privado como propio es un derecho dado al hombre por la naturaleza", vale decir, es casi una categoría netamente humana, añadiendo que "también en esto es grande la diferencia entre el hombre y el género animal". Y tratando de precisar su pensamiento, León XIII nos dice: "el que Dios haya dado la tierra para usufructuarla y disfrutarla a la totalidad del género humano, no puede oponerse en modo alguno a la propiedad privada".

Por otro lado, insiste León XIII, la "totalidad del género humano, sin preocuparse en absoluto de la opinión de algunos pocos en desacuerdo, con la mirada firme en la naturaleza, encontró en la ley de la misma naturaleza el fundamento de la división de bienes y consagró con la práctica de los siglos, la propiedad privada como la más conforme con la naturaleza del hombre y con la pacífica y tranquila convivencia". La afirmación de León XIII no deja lugar a ninguna tipo de duda, en el sentido que no puede existir una auténtica visión cristiana del hombre que no reconozca el legítimo derecho a la propiedad privada. Por otro lado, habría que recordar que el apelo al denominado argumento del "consentimiento universal" para demostrar la legitimidad de la propiedad privada fue también utilizado por Proudhon.

En su condición de Vicario de Cristo, León XIII señala que la propiedad no sólo expresa una auténtica necesidad de la naturaleza humana, sino que ha quedado también expresamente san- 
cionada por las leyes divinas, que prohíben radicalmente incluso el deseo de lo ajeno: "no desearás la mujer de tu prójimo, ni la casa, ni el campo, ni la esclava, ni el buey, ni el asno, ni nada de lo que es suyo", con lo expresamente se reconoce el derecho a la propiedad privada.

Con ciertas reminiscencias medioevales que también se encuentran en Proudhon, el Papa León XIII precisa que "el derecho de dominio atribuido por la naturaleza a cada persona" es "transferido al hombre en cuanto cabeza de familia", por lo que añade: "Más aún, ese derecho es tanto más firme cuanto la persona abarca más en la sociedad doméstica". Con lo dicho no se excluye necesariamente a la mujer del derecho a la propiedad, ni se sanciona el mayorazgo medieval, lo único que se desprende es que para la Iglesia el derecho a la propiedad privada es un derecho natural estrechamente vinculado a la familia. Como ya lo hemos dicho, lo que podría denominarse el aspecto material de la familia es precisamente la propiedad. En todo caso, es una coincidencia más entre lo que señalara Proudhon y la doctrina social de la Iglesia.

Toda auténtica reforma social, por ende, para que sea realmente tal, tiene que mostrar un pleno respeto a la propiedad privada. El Papa León XIII, con toda claridad, señala: "cuando se plantea el problema impostergable de mejorar la condición" de las grandes mayorías se está señalando un deber que debe asumir todo cristiano, pero en todo intento de reforma política que esté de acuerdo a los principios cristianos, también se ha de tener como funda- mental el principio de que la "la propiedad privada ha de conservarse inviolable". Lo que predica el Cristianismo es que la lucha por la justicia social es un deber del cristiano, pero que esta lucha debe apoyarse en el pleno respeto a la propiedad privada.

La razón del bien común, siempre que éste sea evidente, podrá, en el peor de los casos, limitar el uso de la propiedad, pero jamás, nos dice León XIII, pretender "quitar a otro lo que es suyo o, bajo capa de una pretendida igualdad caer sobre las fortunas ajenas". En todo caso, cuando el bien común requiera necesariamente algún tipo de expropiación tiene que darse el previo pago del justiprecio. Sobre esto, repito, no puede existir la menor duda entre lo que está de acuerdo con la visión de la sociedad del Cristianismo y lo que no lo está.

A pesar de las conclusiones aparentemente conservadoras que pudiesen desprenderse de algunas afirmaciones de León XIII, tomadas de modo aislado, el Papa, sin embargo, le otorga a la propiedad privada un clara carácter social, al vincular directa y estrechamente la propiedad con el salario justo. El derecho de propiedad debe considerarse sagrado - dice el Papa León XIII - porque "se apoya en el ahorro que requiere un salario justo". Por lo que también el Papa, en rara similitud con lo que dijera Proudhon, concluye abogando por la universalización de la propiedad, lo que no significa hablar de la propiedad comunitaria, por dos razones fundamentales. En primer lugar, porque la propiedad es algo indispensable para que se dé la familia y, en segundo lugar, 
porque la tranquilidad pública requiere "que la mayor parte de la masa obrera tenga algo en propiedad".

Desde el momento en que, con la "Rerum Novarum", León XIII trataba de oponerse fundamentalmente a las teorías comunistas que en ese entonces recién se iniciaban, tenía que insistir más en el carácter inviolable de la propiedad privada que en la función social que la propiedad debe cumplir. En ese contexto y, no sin razón, León XIII llega incluso a defender la propiedad privada frente a los tributos e impuestos exagerados que podrían llegar a ser confiscatorios, y contradictoriamente defendidos muchas veces por los liberales radicales. Lo sucedido en el Perú sería sólo un ejemplo de ello, donde la prepotencia de la SUNAT llegó, en algún momento, a extremos inconcebibles. Jamás debe olvidarse - dice León XIII - que la propiedad no es el resultado de una Ley promulgada por un gobierno, sino que se apoya en la misma naturaleza humana y en los preceptos divinos.

Para no dejar lugar a dudas y citando sus propias palabras, León XIII señalaba que la propiedad privada "no debe ser absorbida por la dureza de los tributos e impuestos. El derecho de poseer bienes en privado no ha sido dado por Ley, sino por la naturaleza $y$, por tanto, la autoridad pública no puede abolirla, sino solamente moderar su uso y compaginarlo con el bien común".

\section{Pío XI}

El Papa Pío XI, en su encíclica "Quadragesimo Anno" elogia a León XIII por haber defendido de modo tan claro la legitimidad de la propiedad privada, y por haber hecho una distinción que sería fundamental en la doctrina social de la Iglesia y que, por otro lado, muestra una coincidencia más con lo señalado por Proudhon: una cosa es el derecho a la propiedad y otra cosa la posesión, o su ejercicio de dominio o uso, distinción que sería esencial en el posterior desarrollo de la doctrina social de la Iglesia.

A partir de esta distinción, la tarea fundamental para el Magisterio de la Iglesia fue el tratar de encontrar un punto de equilibrio entre los derechos inviolables de la propiedad y los derechos que también genera la posesión de la misma. Dando un paso adelante en la doctrina social de la iglesia, Pío XI señala lo importante que es "determinar la íntima naturaleza de estos deberes y los límites dentro de los cuales deben hallarse circunscritos por las necesidades de la convivencia social tanto el derecho de propiedad como el uso o el ejercicio de dominio".

Es precisamente en el uso o en el ejercicio del dominio donde radica el carácter histórico y, por ende, variable que necesariamente tiene la propiedad, aunque como tal deba ser considerado como un derecho permanente. Como nos enseña el mismo Pío XI: "del mismo modo que los demás elementos de la vida social, el dominio no es absolutamente inmutable... cuán diversas formas ha revestido la propiedad desde aquellas primitivas de los pueblos rudos y salvajes...así como bajo lo regímenes feudales y monarquías hasta los tiempos modernos". 
En este contexto, el derecho a la propiedad privada forma parte esencial de las leyes naturales y divinas, y por tanto es anterior a todo tipo de derecho positivo sancionado por un Estado, pero el uso o el derecho de dominio pertenece, en cambio, al terreno de la sociología y de las decisiones políticas, y por ende es determinado explícitamente por la Legislación positiva. En todo caso, Pío XI reconoce expresamente el derecho que tiene el Estado para delimitar el uso o ejercicio del dominio, y así el autor de la "Quadragesimo Anno", con la especial claridad de pensamiento que lo caracterizaba, nos dice: "Por consiguiente, la autoridad pública puede decretar puntualmente, examinada la verdades necesidad del bien común y teniendo siempre presente la ley tanto natural como divina, qué es lícito y qué no es lícito a los poseedores en el uso de sus bienes".

El problema central reside, pues, en encontrar el punto de equilibrio entre el carácter inviolable de la propiedad y el también legítimo derecho de la autoridad civil de poder reglamentar su uso o disfrute. Este equilibrio indudablemente es siempre un hecho histórico determinado que necesariamente varía de acuerdo al tiempo y al espacio. La solución al problema, sin embargo, es muy difícil de vislumbrar, pues existen peligros innegables. El mismo Papa Pío XI nos pone sobre aviso sobre los peligros que se deben evitar: "hay, por consiguiente, que evitar con todo cuidado los escollos contra los cuales se puede chocar. Pues, igual que negando o suprimiendo el carácter social y público del derecho de propiedad se cae o se incurre en peligro de caer en el individualismo, rechazando o disminuyendo el carácter privado o individual de tal derecho, va necesariamente a dar en el colectivismo".

Por todo esto, en "Divini Redemptoris Promissio", Pío XI insistiría nuevamente en la doctrina secular de la Iglesia acerca del carácter individual que necesariamente tiene la propiedad, pero recordando simultáneamente la exigencia social que debe cumplir la propiedad privada. Por otro lado, el Papa Pío XI recordaba también que, en infinidad de oportunidades, la Iglesia había precisado claramente su posición acerca del derecho y de la mayor dignidad del trabajo en relación con la propiedad, sobre las relaciones de apoyo mutuo y de ayuda que deben existir entre los que tienen el capital y lo que trabajan, y finalmente sobre el salario debido por estricta justicia al obrero que debe ser suficiente para sí y para su familia".

\section{Pío XII}

Siguiendo el pensamiento de Pío XI, su sucesor, el Papa Pío XII, el 1 de junio de 1941, en plena guerra mundial, conmemorando los cincuenta años de la promulgación de la "Rerum Novarum" en la fiesta de Pentecostés, insistía en que el derecho de la propiedad privada se basa exclusivamente en el mismo derecho natural, por lo que tiene que ser respetado, en primer lugar, por la autoridad civil, pues es un derecho que se apoya en el orden preestablecido por Dios y no por decisión de una Legislación humana.

Pío XII, sin embargo, en el mismo sermón de Pentecostés de 1941, también 
acotaba que el derecho de propiedad privada, en modo alguno, debería constituir un obstáculo "para que sea satisfecha la indestructible exigencia que los bienes creados por Dios para provecho de todos los hombres lleguen con equidad a todos, de acuerdo con los principios de la justicia y de la caridad".

Pero fue precisamente en esta época del Pontificado del Pío XII en la que se inició la famosa discusión, que tuvo especial repercusión en la década, sobre el tema de la participación de los trabajadores tanto en la gestión como en la propiedad de las empresas, donde laboran. Como era de esperarse, la Iglesia tenía que mostrarse sumamente cauta en este tema tan complejo. Sin embargo posteriormente, sobre todo en la década de los cincuenta, el Pontificado va a mostrar cierta simpatía sobre este punto, pero sin ocultar sus reparos sobre el intento de hacerla obligatoria.

El 3 de junio de 1950, cuando a nivel mundial se iniciaba la experiencia de las estatizaciones de las empresas productivas y de servicios que tanto daño hicieron a la economía de todos los países en los que se aplicó, sin excepción alguna, en un discurso denominada "Alocución sobre la cogestión", Pío XII hizo la más ardorosa defensa de la empresa privada frente a la intromisión desmedida, peligrosa y creciente del Estado con relación a los derechos naturales de la persona humana. Con el tono de solemnidad que le era característico, Pío XII proclamó: "Declaro en esta alocución que empresa y explotación son instituciones de derecho privado, no ya de derecho público". Por este motivo, Pío XII rechazó tajantemente la intromisión del Estado, como un atentado contra el derecho natural de las personas, frente al proyecto que pretendía obligar a las empresas a que los trabajadores participen en la propiedad y por ende en la gestión de las mismas. Puesto que "ni la naturaleza del contrato de trabajo ni la naturaleza de la empresa llevan por si mismas un derecho a la congestión económica; que, por tanto, no existe la necesidad intrínseca de modelar el contrato de trabajo sobre el contrato de sociedad".

En dicha alocución, Pío XII no se oponía tanto a lo que podríamos denominar el modelo de la "cogestión" cuanto a la intención de hacerla obligatoria, esto es, imponerla mediante una Ley expresa, lo que es algo completamente distinto. Una cosa es propiciar y apoyar la creación de Empresas cogestionarias y otra el tratar de hacer que todas las Empresas privadas se conviertan en tales. El 19 de septiembre de 1952, en carta enviada a la Semana Católica de Turín, tratando de precisar su pensamiento sobre "cogestión", el mismo Pío XII precisaba: "pero esto no veda a los empresarios el que hagan participar en ella (en la gestión de la Empresa) a los obreros en cualquier forma y medida, como no impide al Estado conferir al trabajo la facultad de hacer oír su voz en la gestión de ciertas empresas y en determinados casos en que el poder excesivo del capital anónimo, abandonado a sí mismo, dañe manifiestamente a la comunidad". A lo que se oponía Pío XII era únicamente al deseo de hacer de la "cogestión" una norma universal y obligatoria, cuando debía tener sólo el carácter de excepción. 
Sobre este punto, posteriormente los Papas Juan XXIII y Paulo VI harían aportes muy valiosos.

\section{Juan XXIII}

El Papa Juan XXIII. En su encíclica "Mater et Magistra", continuando la trayectoria de la doctrina social de la Iglesia, insiste en la clara defensa del derecho a la propiedad privada, a la que considera como uno de los fundamentos más sólidos de la libertad. "El derecho a la propiedad privada - proclamaba "ex catedra" Juan XXIII - aún en lo tocante a los bienes de producción, tiene un valor permanente, ya que es un derecho contenido en la misma naturaleza... Además, la historia y la experiencia demuestran que en los regímenes políticos que no reconocen a los particulares la propiedad, incluido la de los bienes de producción, se viola o se suprime totalmente el ejercicio de la libertad humana". Indudablemente existe una estrecha relación entre el derecho a la propiedad y el ejercicio de la libertad, por lo que la propiedad termina siendo el más fuerte contrapeso de la autoridad omnímoda que todo Estada, por su misma naturaleza, quisiera tener, tal como ya lo había previsto admonitoriamente Proudhon.

Y más adelante, el Papa Roncalli, nuevamente insistiría en que la propiedad privada "asegura los derechos que la libertad concede a la persona humana", por lo que al mismo tiempo, "presta su necesaria colaboración para restablecer el recto orden de la sociedad". Vale decir, para la Iglesia no puede haber libertad sin derecho a la propiedad. Pero al igual que sus predecesores, Juan XXIII también recalcaría la función social que siempre debe cumplir la propiedad privada. Para Juan XXIII la necesaria proyección social de la propiedad "toma su fuerza del propio derecho de propiedad".

\section{Paulo VI}

La encíclica "Populorum Progressio" del Papa Pablo VI constituye, sin duda alguna, uno de los hitos más importantes en el desarrollo de la doctrina social de la Iglesia en general, y sobre su posición acerca del derecho a la propiedad privada en especial. Citando a San Ambrosio, maestro de San Agustín y antecesor del mismo Paulo VI en la arquidiócesis de Milán, el Papa Montini señalaba: "No es parte de tus bienes lo que tú das al pobre; lo que le das le pertenece. Porque lo que ha sido dado para el uso de todos, tú te lo apropias. La tierra ha sido dada para todo el mundo y no solamente para los ricos". Es exactamente lo mismo que enseñara, muchos siglos antes, Santo Tomás de Aquino.

Partiendo, pues de las enseñanzas de los Padres y Doctores de la Iglesia, es que el Papa Paulo VI, sin desconocer el derecho natural a la propiedad privada sancionado incluso por preceptos divinos, va a precisar que "la propiedad privada" no constituye para nadie un derecho incondicional y absoluto. No hay ninguna razón para reservarse en uso exclusivo lo que supera a la propia necesidad cuando a los demás les falta lo necesario. En una palabra, el derecho de propiedad no debe jamás ejercitarse con detrimento de la utilidad común, según la doctrina tradicional de los Padres de la Iglesia y de los grandes teólogos". La 
voz de Paulo VI fue tal vez la más radical en señalar que la propiedad privada sólo se justifica cuando tiende al bien común y se adecua plenamente a las exigencias de la justicia.

Como lógica consecuencia, el Papa Paulo VI incluso defiende, siempre y cuando sea realmente indispensable para el bien común, el derecho del Estado a expropiar la propiedad privada, que no es lo mismo que confiscar. Y así, el Papa Mortini nos dice: "El bien común exige, algunas veces, la expropiación si, por el hecho de su extensión, de su explotación deficiente o nula, de la miseria que de ello resulta a la población, del daño considerable producido a los intereses del país, algunas posesiones sirven de obstáculo a la propiedad colectiva". Pero todo ello, reiteramos, sólo tiene el carácter de excepción frente a la regla general del derecho a la propiedad, y sólo se justifica por el "bien común" que está en juego, y no por algún tipo de cálculo político.

Por otro lado, siguiendo el viejo refrán que "la caridad empieza por casa", el Papa Paulo VI afirmaba que la riqueza que produce un país debería también redundar fundamentalmente en beneficio del mismo. No es admisible ni a la justicia ni a la función social que siempre debe cumplir la propiedad, la fuga de capitales, por más que quiera apoyarse en los derechos inalienables de la propiedad privada. La riqueza de una nación les pertenece a todos y no sólo a algunos. El Papa Paulo VI expresamente dice: "Desde luego, no se podría admitir que ciudadanos provistos de rentas abundantes, provenientes de los recursos y de la actividad nacional, los transfieran en parte considerable al extranjero por puro provecho personal, sin preocuparse del daño evidente que con ello infligen a la propia patria".

En resumen, de acuerdo al magisterio del Papa Paulo VI, es una auténtica exigencia cristiana el reconocer el derecho de la propiedad privada, pero también lo es el tomar conciencia de sus límites y de las obligaciones sociales que necesariamente trae consigo. Son también exigencias cristianas el reconocer el derecho del Estado a reglamentar el uso de la propiedad tal como ya lo había señalado también el Papa Pío XI, y hasta expropiar pero sólo en los poquísimos casos en los que así lo exija realmente el bien común. El Estado debe también tratar impedir, por todos los medios a su alcance, la fuga de divisas y capitales que tanto daño hacen a una colectividad nacional.

\section{Juan Pablo II}

El Papa Juan Pablo II, en “Laborem Exercens" reitera lo señalado por el Papa Paulo VI en lo que se refiere tanto al derecho como a los alcances de la propiedad privada. "La tradición cristiana - nos recuerda al Papa polaco-jamás ha defendido a este derecho como algo absoluto e intocable. Al contrario, siempre lo ha entendido dentro del más amplio contexto del derecho de todos a usar los bienes de toda la creación: el derecho de la propiedad privada como subordinado al derecho del uso común, al destino universal de los bienes". La cita nuevamente no deja lugar a dudas sobre la posición cristiana sobre la propiedad, como un instrumento vinculado al desarrollo y al bienestar social. 
El Papa Juan Pablo II, sin embargo, llega más allá. Subordina el derecho de la propiedad al derecho del trabajo y habla incluso de la necesidad de un real proceso de socialización de ciertos medios de producción, que es todo lo contrario a lo que se propuso el socialismo histórico. Refiriéndose precisamente a los medios de producción, que es el punto donde fundamentalmente se ubica la discusión sobre el tema de la propiedad privada, Juan Pablo II dice que "no pueden ser poseídos contra el trabajo, tampoco pueden ser poseídos por poseer, porque el único título legítimo a su posesión - tanto en lo que se refiere a la propiedad privada, como al de la pública y a la colectiva - es que ella sirva al trabajo; y que, por consiguiente, sirviendo al trabajo, hagan posible la realización del primer principio que es el destino universal de los bienes y el derecho de su uso común. Desde este punto de vista... no se puede excluir la socialización de ciertos medios de producción". Quien no esté dispuesto a repetir lo mismo no tendría derecho a denominarse cristiano.

Lo dicho significa que la doctrina social de la Iglesia rechaza la interpretación del liberalismo, entendido como una determinada ideología histórica, sobre la propiedad, fundamentalmente en lo que se refiere a los medios de producción. Más aún en aras del derecho del trabajo, de acuerdo a la doctrina social de la Iglesia, se podría y hasta se debería revisar toda la doctrina acerca de la propiedad de los medios de producción. Al respecto, Juan Pablo II nos dice: "continúa siendo inaceptable la posición del rígido capitalismo, que defiende el exclusivo derecho de la propiedad privada de los medios de producción como un dogma intocable en la vida económica. El principio del respeto del trabajo exige que este derecho sea sometido a una revisión constructiva, sea en la teoría como en la práctica”.

La uténtica socialización de la propiedad sobre todo de los medios de producción no es contraria, pues, a la doctrina social de la Iglesia. Sin embargo, el papa Juan Pablo II distingue claramente entre socialización y estatismo, señalando que éste último mantiene todas las lacras de la propiedad privada entendida bajo la misma óptica del rígido capitalismo. Punto que nuevamente recuerda las enseñanzas de Proudhon y que fueron divulgadas en América Latina por Víctor Raúl Haya de la Torre.

Y así tras atacar duramente el monopolio de la administración central, en la que el Estado tiende a reemplazar tanto a la propiedad como a la iniciativa privada, generando sólo la ineficiencia económica y la pobreza generalizada, Juan Pablo II nos dice: "el solo paso de los medios de producción a propiedad del Estado, en el sistema colectivista, no equivale a la socialización de la propiedad. Se puede hablar de socialización sólo cuando se asegure a cada persona, en base de su propio trabajo, el pleno derecho de considerarse copropietarios". Dicha crítica también sería válida para cierto cooperativismo mal entendido, donde las personas concretas en el fondo no fueron ni son dueñas de nada, tal como se patentizó en el caso peruano. Tal vez por haberlo sufrido en 
carne propia, el Papa Juan Pablo II tenía necesariamente que condenar expresamente el llamado "capitalismo de Estado" que se implantó con el pomposo nombre de "socialismo", y que jamás se propuso la real socialización de los bienes, sino todo lo contrario su plena concentración, en manos de la cúpula que ejercía dictatorialmente el poder.

En su posterior encíclica "Sollictudo Rei Sociales", Juan Pablo II, sintetizando admirablemente el pensamiento social de la Iglesia sobre el tema de la propiedad, señala: "el mal no consiste en el tener como tal, sino en el poseer que no respeta la calidad y la ordenada jerarquía de los bienes que se tienen". De lo que se trata es de restablecer una jerarquía de valores, que esté realmente de acuerdo con la dignidad de la persona humana, con el fin de elevarla y no de denigrarla. Vale decir, no se debería olvidar tan fácilmente las antinomias entre "ser" y "tener", sobre todo cuando el "tener" de algunos puede ser a expensas del "ser" de las grandes mayorías populares.

Para Juan Pablo II quien tiene que empezar a dar ejemplo de lo dicho es la misma Iglesia. Y así, del modo más claro, proclama: "ante los casos de necesidad no se debe dar preferencia a los adornos superfluos de los templos y a los objetos preciosos del culto divino; al contrario, podría ser obligatorio enajenar estos bienes para dar pan, bebida, vestido y casa a quien carece de ellos". Creo que es lo que trató de hacer como dignísimo Obispo de Puno, nuestro queridísimo Maestro, Monseñor Julio González Ruiz, quien vivió como santo y murió como mártir, símbolo pleno de la fidelidad a la
Iglesia y a la Congregación Salesiana, a pesar de las incomprensiones sufridas.

Sintetizando la posición de la Iglesia sobre el derecho de la propiedad privada, Juan Pablo II nos dice: "es necesario recordar, una vez más aquel principio peculiar de la doctrina cristiana: los bienes de este mundo están originariamente destinados a todos. El derecho a la propiedad privada es válido y necesario, pero no anula el valor de tal principio. En efecto, sobre ella grava "una hipoteca social", es decir, posee como cualidad intrínseca, una función social fundada y justificada sobre el principio del destino universal de los bienes". Por supuesto, sin olvidar el derecho natural a la iniciativa económica, sin la cual no es posible progreso alguno.

Pero el Papa Juan Pablo II describe también, en toda su magnitud, las secuelas negativas que el estatismo produjo fundamentalmente en los países del tercer mundo y que los colocó en una clara situación de inferioridad y de desventaja frente a sus competidores, en una economía que cada día se internacionaliza más, por lo que termino siendo tal vez el mayor responsable de la pobreza generada de dichos pueblos. El Estado, en todo caso, sólo debería regentar las empresas realmente estratégicas, pero todo lo demás debe quedar exclusivamente dentro de la libre iniciativa privada.

En la última encíclica social "Centesimus Annus", Juan Pablo II recuerda que en la "Rerum Novarum", el Papa León XIII afirmaba, enérgicamente y con varios argumentos tanto de carácter natural como religioso, el 
derecho a la propiedad privada en contra de lo que propiciaba el socialismo de dicha época. De modo especial, León XIII consideraba que el derecho a la propiedad privada era fundamental para la autonomía y para el desarrollo de la persona humana, que era producto de una ley natural que tenía que ser reconocida como tal en la legislación positiva, por lo que - señala Juan Pablo II - siempre fue defendido por la Iglesia, de modo especial en los últimos cien años.

Pero también- recuerda Juan Pablo II - el Papa León XIII fue plenamente consciente que la propiedad privada no es un derecho absoluto, "ya que en su misma naturaleza de derecho humano lleva inscrita su propia limitación”. Es por este motivo, por el que el Papa León XIII también proclamó los principios que necesariamente complementan sin anular la propiedad, como sería, por ejemplo, el destino universal de los bienes de la tierra.

Por otro lado, termina comentando Juan Pablo II, necesariamente el Papa León XIII tenía que hablar fundamentalmente sobre el tipo de propiedad más representativa en su época. En ese contexto, "no cabe duda de que el tipo de propiedad privada, que León XIII considera principalmente, es el de la propiedad de la tierra", que era el prototipo de la propiedad en ese entonces. En tiempos de León XIII hablar de propiedad era fundamentalmente hablar de la propiedad de la tierra, posteriormente la propiedad de los bienes de producción reemplazaría en importancia a la propiedad de la tierra a la que terminó subordinando, mientras que actualmente nos encontramos con un nuevo tipo de propiedad, la propiedad de los conocimientos técnicos que reviste mayor importancia que todos los anteriores tipos de propiedad que se le van haciendo cada vez más dependientes. $Y$ en el caso peruano, habría que hablar de la propiedad vinculada al comercio y a las importaciones, que han llegado a destruir la industria nacional y que se apoya naturalmente en el poder político.

Sin embargo, habría que insistir que todos los sucesores del Papa León XIII han repetido siempre la doble afirmación que hiciera el iniciador de la doctrina social de la Iglesia: la necesidad y, por tanto, la licitud de la propiedad privada, pero también los límites que pesan sobre ella, fundamentalmente por la función social que siempre debe cumplir. Y ello debe aplicarse tanto a la propiedad de la tierra como a la propiedad de los bienes de producción y a los nuevos tipos de propiedad que aparezcan a través del tiempo.

Jamás debe olvidarse - proclama Juan Pablo II, en pleno auge del neoliberalismo - que el origen primigenio de todo lo que es un bien natural hay que buscarlo en el acto mismo de Dios que ha creado el mundo como ha creado al hombre, y que otorgó la tierra al hombre para que la domine con su trabajo y goce solidariamente de sus frutos. Vale decir, "Dios ha dado la tierra a todo el género humano para que ella sustente a todos sus habitantes, sin excluir a nadie ni privilegiar a ninguno. He ahí, pues, la raíz primera del destino universal de los bienes de la tierra". Pues bien, es a este destino primigenio, que reitero fuera señalado siglos atrás por Santo Tomás de Aquino, al que tiene que adecuarse el derecho de la propiedad privada. 
Continuando su argumentación, el Papa Juan Pablo II añade: "ahora bien, la tierra no da sus frutos, sin una peculiar respuesta del hombre al don de Dios, es decir, sin el trabajo. Es mediante el trabajo como el hombre, usando su inteligencia y su libertad, logra dominarla y hacer de ella su digna morada. De este modo, se apropia de una parte de la tierra, la que ha conquistado con su trabajo: he ahí el origen de la propiedad individual". Desde su origen, pues, la propiedad esta ligada al trabajo.

En todo el tema de la propiedad privada, siguiendo la lógica de la Doctrina Social de la Iglesia, podríamos considerar que existe, una permanente confrontación dialéctica entra la tierra o, para precisarlo mejor, la materia inerte, entendida en su pleno sentido escolástico y el trabajo: la materia que como tal es siempre indeterminada, ha sido otorgada por Dios como patrimonio a todo el género humano. Por lo que es el trabajo el que determina, da forma, individualiza $y$, por ende, el que da origen a la propiedad privada. El fruto de ello debería ser sólo el fortalecimiento y crecimiento del bien común.

Juan Pablo II nos describe del siguiente modo la tensión dialéctica que seda entre la tierra y la propiedad: "A lo largo de la historia, en los comienzos de toda sociedad humana, encontramos siempre estos dos factores, el trabajo y la tierra; en cambio, no siempre, hay en entre ellos la misma relación. En otros tiempos, la natural fecundidad de la tierra aparecía, y era de hecho, como el factor principal de riqueza, mientras que el trabajo servía de ayuda y favorecía a tal fecundidad. En nuestro tiempo, es cada vez más importante el papel del trabajo humano en cuanto factor productivo de las riquezas inmateriales y materiales; por otra parte, es evidente que el trabajo de un hombre se conecta naturalmente con el de otros hombres. Hoy más que nunca, trabajar es trabajar con otros y para otros, es hacer algo para alguien”.

Hoy en día, como ya señaláramos, la situación sobre la preponderancia de los diversos tipos de propiedad se ha modificado substancialmente. No sólo la propiedad de la tierra ha pasado a segundo plano, sino lo mismo tiende a suceder con la propiedad de los bienes de producción. Como nos dice Juan Pablo II: "existe otra clase de propiedad, concretamente en nuestro tiempo, que tiene una importancia no inferior a la de la tierra: es la propiedad del conocimiento, de la técnica y del saber". Pues bien, es "en este tipo de propiedad, mucho más que en los recursos naturales, donde se funda la riqueza de las naciones industrializadas"39. La importancia de este tema se ha evidenciado en las conversaciones que se fueron dando entre los países latinoamericanos y los EEUU al tratar el tema del "Tratado del Libre Comercio". Pero también este tipo de propiedad debe redundar en beneficio del "bien común", aunque en este caso, por su propia naturaleza, sea una propiedad inconfiscable por parte del Estado.

Aquí radica una de las grandes fuentes de los cambios radicales que se han operado en el mundo contemporáneo, que se expresa indudablemente en la dinámica del mundo social, y que ha hecho anacrónica a todas las diversas manifestaciones históricas del socia- 
lismo, y que incluso obligan a superar mucho de la doctrina aprista. No se puede desconocer que hay diferencias específicas entre las tendencias a la propiedad de la sociedad moderna y las del pasado, incluso el más reciente, de las que partieron las doctrinas socialistas. Como señala Juan Pablo II: "si en otros tiempos, el factor decisivo de la producción era la tierra y luego fue el capital, entendido como conjunto masivo de maquinarias y bienes industriales, hoy día el factor decisivo es cada vez más el hombre mismo, es decir, su capacidad de organización solidaria, así como la de intuir y la de satisfacer las necesidades de los demás". Este hecho trastoca muchas cosas, entre ellas, el conflicto y la determinación actual de las clases sociales, así como el mismo fenómeno imperialista.

Juan Pablo II anota que incluso la capacidad de conocer oportunamente las necesidades de los demás hombres y planificar el conjunto de los factores productivos más apropiados para satisfacerlos, "es otra fuente importante de riqueza en una sociedad moderna", lo que está también estrechamente relacionado con un nuevo tipo de propiedad. Por lo demás, muchos bienes no pueden ser ya producidos aisladamente, sino que exigen la colaboración de muchos factores, incluso de naturaleza internacional, pues bien, "organizar ese esfuerzo productivo, programar su duración en el tiempo, procurar que corresponda de una manera positiva a las necesidades que debe satisfacer, asumiendo los riesgos necesarios: todo esto es también una fuente de riqueza en la sociedad actual".

Vale decir, nos encontramos con una nueva pero auténtica clase social, conformada por profesionales en finanzas, mercadeo, planificación, informática etc. Que no tienen nada que ver con las clases tradicionales de burguesía y proletariado, y que son manifestaciones de una nuevo tipo de propiedad, el de la técnica. Actualmente, en muchos casos, esta propiedad es más importante que la de la tierra y la de los bienes de capital. Este es un real signo de los tiempos contemporáneos, que ningún político debería desconocer, al margen repito, que ha vuelto anacrónicas a la mayor parte de las teorías sociales, hasta hace poco vigentes.

Retomando al tema de la propiedad, Juan Pablo II manteniéndose como era de esperarse dentro de los cánones de la tradición de la Iglesia, la defiende ardorosamente, pero también reconoce que existen muchos abusos y que, cuando ello se da la propiedad privada de ningún modo se podría justificar éticamente: "La propiedad de los medios de producción, tanto en el campo industrial como agrícola, es justa y legítima cuando se emplea para un trabajo útil; pero resulta ilegítima cuando no es valorada o sirve para impedir el trabajo de los demás u obtener unas ganancias que no son fruto de la expansión global del trabajo y de la riqueza social, sino más bien de su comprensión, de la explotación ilícita, de la especulación y de la ruptura de la solidaridad en el mundo laboral. Este tipo de propiedad no tiene ninguna justificación y constituye un abuso ante Dios y ante los hombres".

Por este motivo, Juan Pablo II concluye diciendo: "Así como la persona 
se realiza plenamente en la libre donación de sí misma, así también la propiedad se justifica moralmente cuando crea, en los debidos modos y circunstancias, oportunidades de trabajo y crecimiento humano para todos". Y aquí radica precisamente el Talón de Aquiles del Liberalismo, su implantación en una realidad determinada hasta el momento sólo ha generado un mayor desempleo en todos los países donde se ha aplicado y aparentemente se ha convertido en un obstáculo insalvable para el "crecimiento humano para todos". Este hecho no sólo se expresa en los países pobres sino también y, de modo cada vez más creciente, en los mismos países desarrollados. En esta incluso la idea directriz de la denominada "antiglobalización" que es la expresión del descontento, en los países ricos, del pueblo que sufre la carencia de trabajo y con ello la imposibilidad de poder subsistir con un mínimo de dignidad.

\section{Conclusiones}

1) El Cristianismo considera como imperativo ético el defender la prioridad que tiene el trabajo sobre el capital, por su carácter determinante en la creación histórica de la misma propiedad, sea cualquiera el sistema político que se adopte. Al respecto, Juan Pablo II nos dice: "el principio de la prioridad del trabajo en la confrontación con el capital des un postulado que pertenece al orden de la moral social. Tal postulado tiene su importancia clave tanto en el sistema construido bajo el principio de la propiedad privada de los medios de producción, como en los sistemas en los que la propiedad privada de estos medios está radicalmente limitada".

2) Como se puede apreciar, en la doctrina social de la Iglesia hay una lógica evolución en lo que se refiere a las manifestaciones históricas de la propiedad, pero enmarcada dentro de la más estricta continuidad de pensamiento en lo que se refiere el derecho natural a la propiedad. León XIII hace la más ardorosa defensa de la propiedad privada, pero haciendo una clara distinción entre el derecho a la propiedad y el uso o disfrute de dicho derecho. El Papa Pío XI, en la "Quadragesimo Anno", señala que el uso o ejercicio del dominio de la propiedad tiene un claro carácter histórico, por lo que puede y debe ser reglamentado por el Estado, pero insistiendo que la propiedad como tal no es un derecho que otorga el Estado a los individuos.

3) El Papa Pío XII, en diversas alocuciones, también subordina el derecho de la propiedad al bien común de una colectividad.

4) El Papa Juan XXIII nuevamente defiende la propiedad privada como fundamento real y objetivo de la libertad, y por ende, como el mejor límite al poder del Estado tal como también lo había señalado Proudhon, pero recalcando también la función social que debe cumplir la propiedad.

5) Con Paulo VI, la Iglesia recuerda fundamentalmente que la propiedad, por su misma esencia, no es un derecho absoluto, por lo que está 
subordinado al bien o a la utilidad común. El Papa Paulo VI defiende también el derecho del Estado a la expropiación, cuando así lo requiera el bien común y sea considerada como una excepción y no una norma generalizada. Del mismo modo, el Papa Montini defiende el derecho del Estado a regular la salida de capitales y de divisas que, no sólo pertenece a los privados, sino que conforman fundamentalmente un patrimonio nacional.

6) El Papa Juan Pablo II continuó plenamente la línea señalada por su predecesor, Paulo VI. Insistiendo en la subordinación del capital al trabajo y hasta llega a defender la necesidad de un sano y equilibrado proceso de socialización de los medio de producción, que nada tienen que ver con el proyecto socialista. Y, por último, el actual Pontífice señala que existe una "hipoteca social" que grava todo tipo de propiedad privada. Pero con la misma insistencia, Juan Pablo II condena también y de modo expreso el estatismo ineficiente que tanto daño ha hecho sobre todo a los países del llamado tercer mundo. Pero tal vez, y de modo especial, reviste una especial trascendencia histórica la interesante reflexión que hacer el actual Pontífice sobre la importancia que en la historia han ido tomando las diversas formas de propiedad, por lo que el reducir el complejo tema de la justicia social al tema de la tierra y de los medios de producción es mantenerse dentro de una mentalidad propia de una época ya superada. 


\section{Referencias}

- León XIII, Enc. Rerum Novarum, Roma, (15-V - 1891)

- Pio XI, Enc. Quadragessimo anno Roma (15-V-1931)

- Juan XXIII, Enc. Mater et Magistra, Roma, (15-V-1961) nc. Pacem in terris, Roma (11 - IV 1963)

- Pablo VI, Enc. Populorum progressio, Roma, (26-III - 1967)

- Juan Pablo II, Enc. Laborem Exercens, Roma, (14-IX - 1981) Enc. Sollicitudo Rei Socialis, Roma, (30 - XII - 1987)

- Concilio Ecuménico Vaticano II.(1965). Const. Gaudium et Spes.
- Antoncich, Ricardo-Munárriz, José M. (1988). La Doctrina Social de la Iglesia. Madrid. Paulinas.

- Arzobispado de Lima. (1991). La Iglesia ante el desafío de lo social. Lima. Editorial Latina.

Galindo García, Ángel. (1996). Moral socioeconómica. Madrid. BAC.

- Herr, Theodor. (1990). Doctrina Social Católica. V. Hase \& Koehler Verlag Mainz, Germany.

- Herrrera, Roberto. (1988). Introducción a la Doctrina Social de la Iglesia. 2da. ed., Santiago de Chile. Paulinas. 